\title{
Simulation and prototyping benefits on digital fabrication
}

\section{Teaching experience on previous workshops}

\author{
Pablo Baquero \\ Faberarium, Colombia \\ paniba@faberarium.org \\ Victor Calixto \\ UNICAMP, Brasil \\ arq.victorcalixto@gmail.com
}

\author{
Affonso Orciuoli \\ ESARQ UIC, Spain \\ orciuoli@gmail.com \\ Charles C Vincent \\ Presbyterian University Mackenzie, Brasil \\ charles.vincent@mackenzie.br
}

\begin{abstract} Sigradi (Florianopolis 2015).

Keywords: Teaching, 3D printing, Milling, Patterns, Collaboration, Fabrication.

\section{Introduction}

Simulation is critical on manufacturing strategies. Manufacturing systems, processes, and data are growing ever more complex. Product design, manufacturing engineering, and production management decisions often involve the consideration of many interdependent variables - probably too many for the human mind to reach with at one time. These decisions often have a long term impact on the success or failure of the manufacturing organization. Simulation provides a capability to rapidly conduct experiments to predict and evaluate the results of alternative manufacturing decisions. It has often been said that you do not really understand your industrial processes and systems until you try to simulate them. Industry technology leaders in many sectors, e.g., aerospace and automotive manufacturers, are making greater and greater commitment to the use of manufacturing simulation in the various stages of their manufacturing processes. ${ }^{1}$ With these premises the students have been motivated to come up with practical ways to deal with new technologies and apply them in manufacturing, but specially in parametric techniques that aids analysis of solutions applied to the project proposed for construction.
\end{abstract}

This paper explains how parametric methods are informed by simulation and prototyping, methods that were deployed during some series of digital fabrication workshops, their evolution and specifically with the objective of fabricating using combination of materials and CNC techniques, such as, 3d printing, laser cutting and milling machine. Teaching these workshops were the results of simulating and prototyping with students from the Biodigital Master (ESARQ UIC 2016) and a workshop done during

The workshops used Rhinoceros and Grasshopper as ground base to exchange the team process and develop a proposed project. Merging digital manufacture methods, has the advantage of understanding the clearance spaces and tolerances. Additionally, to understand the importance of preparing the geometry for the different CNC methods.

\footnotetext{
${ }^{1}$ See at Charles McLean and Swee Leong, "The Role of Simulation in Strategic Planning," in Proceedings of the 2001 International Working Conference on Strategic Manufacturing (Aalborg, 2001).
}

Throughout the fabrication process students would understand from the basic to advanced levels. The Master BioDigital Architecture ${ }^{2}$ students develop series of projects related to digital design strategies. The workshop's main idea was to prepare students to deal with digital fabrication machines, then learn how to prepare files for production models.

Strategically the workshop is given right at the beginning of the master. As seen below, the exercise needed for proper coordination between the parties, thus achieving the fit and assembly of all components. Thus, we have demonstrated the accuracy and efficiency of the machine. This initial input has aroused the curiosity and examples presented allowed a broad reading on digital design and fabrication, always marked by a speculative nature and seeks innovation.

\section{Methodologies}

Gathering some researchers and students from two continents and working online. Synchronously and experimenting with parametric modeling of a shell project to be fabricated using laser cutters, 3d printers and milling machine was of the ground base. The team used Rhino's Grasshopper and a few plugins for parametric modelling to learn not only to program but led through a broader understanding of the design process, one in which design is understood as an experiment.

Prototyping is one of the design verification means, along with algorithm examination. Thus, prototyping is used along the programming phases to check parts feasibility and connections to provide real world feedback to the

\footnotetext{
2 "Biodigital Architecture Master" visited on 21 june. 2016 http://www.biodigitalarchitecture.com
} 


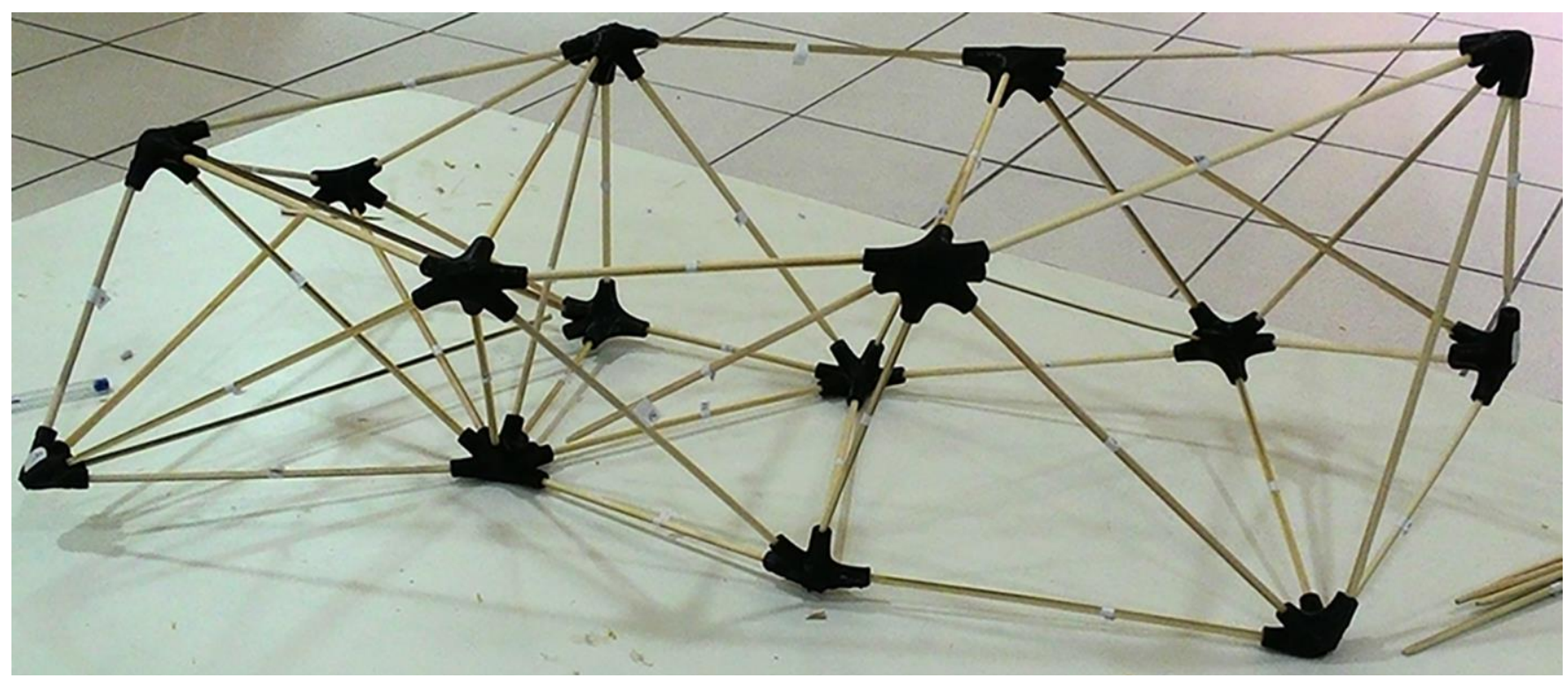

Figure 1 Sigradi workshop 2015 (Florianópolis, Brazil) connectivity was constraint to the number of bars and proximity its neighbors.

programming cycles. These cycles aren't clearly alternated; instead, they happen in such a manner that one can hardly distinguish what is real from what is virtual. Parts of the team might be in a virtual cycle -programming and modelling, while others would be prototyping parts and testing physical models for design alternatives. This entailed random inputs from team members and an important part of the experiment; to learn how to cope with different views of design at first hand. The experiment was an amalgamation of different techniques, one already tested before and design code sets in advance and available for use during a week, which was a limited time for the class.

The workshop methodology is based on Sennett's (2009) assumption that in the learning process both the techniques and their applications come in hand or in other terms the learning is in fact a learn by doing process. ${ }^{3}$

\section{Developed process}

The evolution of teaching process has been in different manners, since all have focused in fabrication processes with a previously designed project, and with mostly short time to explore for design alternatives. This has been an advantage, having this limitation because the goal was to focus in the tool's possibilities instead of imposing design to the tools employed.

The workshops were divided in four main focus areas: Basic $3 d$ modelling in Rhino, concepts of $3 d$ printing, introduction to parametric modelling in Grasshopper and 3d printing. After the students had an introduction to the parametric modelling tools, that was composed by incremental Grasshopper codes and a previously prepared code of the spatial structure, due to the fact that we had only two days to teach basics concepts about three different issues. This introductory class allowed them to test by their own the spatial structure's code by altering specific parameters.

\section{Joints and Connectivity}

Another interesting experience has been from Sigradi 2015, (Florianópolis, Brazil) workshop that we had taught, lead us to understand the possibilities of 3D printing to create customized joints for spatial structures (see Fig.1). The main idea of that workshop was to introduce students to 3D printing basic techniques, using parametric modelling tools. One of the crucial concepts of the design was taking into account the type of connectivity which was constrained to each joint, based on the proximity to each other and its quantity of connections.

Some other key concepts of 3D printing, explored in both workshops, included the relation of geometry with the printer's capacities, like which possible geometries we can do with different kinds of 3D printers, and how we can prepare the STL files and the G-code to the machine.

\section{D Voronoi space frame}

As researchers and teachers, the spatial tessellation concept was always a concern to an architectonical approach in the project. We used a 3D voronoi logarithm to achieve this on the latest workshop taught at Esarq UIC, by the Biodigital Master team. Fabrication techniques were explored in three different phases of the process: 3D printing, milling machine and Laser Cutting. As the 3D printing methods were experienced previously in Florianópolis workshop, and resulted as an input for the Biodigital Architecture fabrication workshop.

By means of different materials and geometric solutions were prototyped, the team could assess the suitability of each design variation and readjust parameters. One of the main

\footnotetext{
${ }^{3}$ See SENNETT, Richard. El artesano. Anagrama, Barcelona 2009.
} 
difficulties on designing the joints was to be able to have a flat

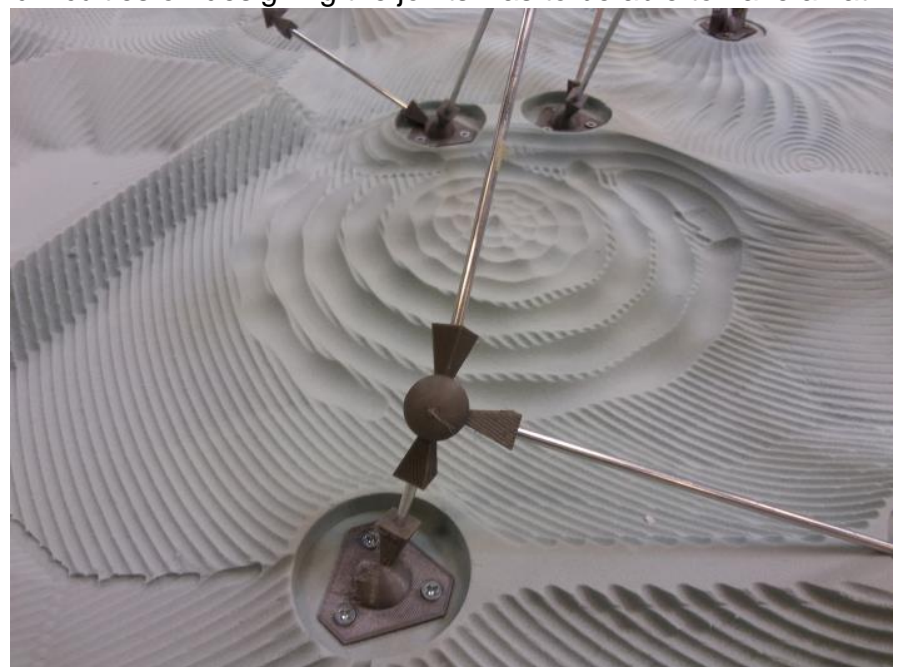

Figure 3. Connection 3D printed with flexible filament anchored with three screws to a foam base.

surface to add a number for each aluminum bar connection. So the joint had the IDs of the bars connecting on it. Organizing and orienting $3 \mathrm{D}$ print joints on the machine bed size was important for later on to be able to locate them spatially during the assembly process. We used flexible material filament for the joints, since those would adjust better for closing the first to the last of the aluminum bars and smaller tolerances.

Spatial cells that came out of the $3 d$ voronoi have always planar faces but some connecting bar became very short that some joints were colliding it selves geometrically, for this reason we applied a logarithm that merged vertices that are closer than double the size of the joint.

\section{Milling patterns}

Simulation using Rhinocam aided in the design process since the subtraction process from one tool to the other needed to be taken into account for the final piece. The foam panel was divided using Voronoi patterns for each student's design. For this reason, the coordination of the Rhinocam files was essential in order to compile all of them into one milling file.

Initially, the fabrication sequence started by doing a roughing process with a $50 \mathrm{~mm}$ ball to the overall foam panel. Then, the finishing mill process was done by a few milling tools diameters depending on the design decision by each student. On the joint connectors, it needed some special treatment, and the drill process was made in order to be able to anchor the 3D printed joints to the foam with screws. (see Fig. 2)

\section{Discussion}

The workshops taught by the teachers and authors of this article had as main objective always the final physical materialization of objects based on the digital fabrication machines, which was useful by utilizing parametric design.

These materializations are results of a process that begins with a design intention, design using vector formats, manipulation of different file extensions according to function's machine and technology to be used, and ending finally machine programming and fabricating. On this process we intend to link different machine and materials, making all to come together as a unite result. As an implicit manner, tolerances, connections, behavior on combining variable materials, required to be exam a priori.

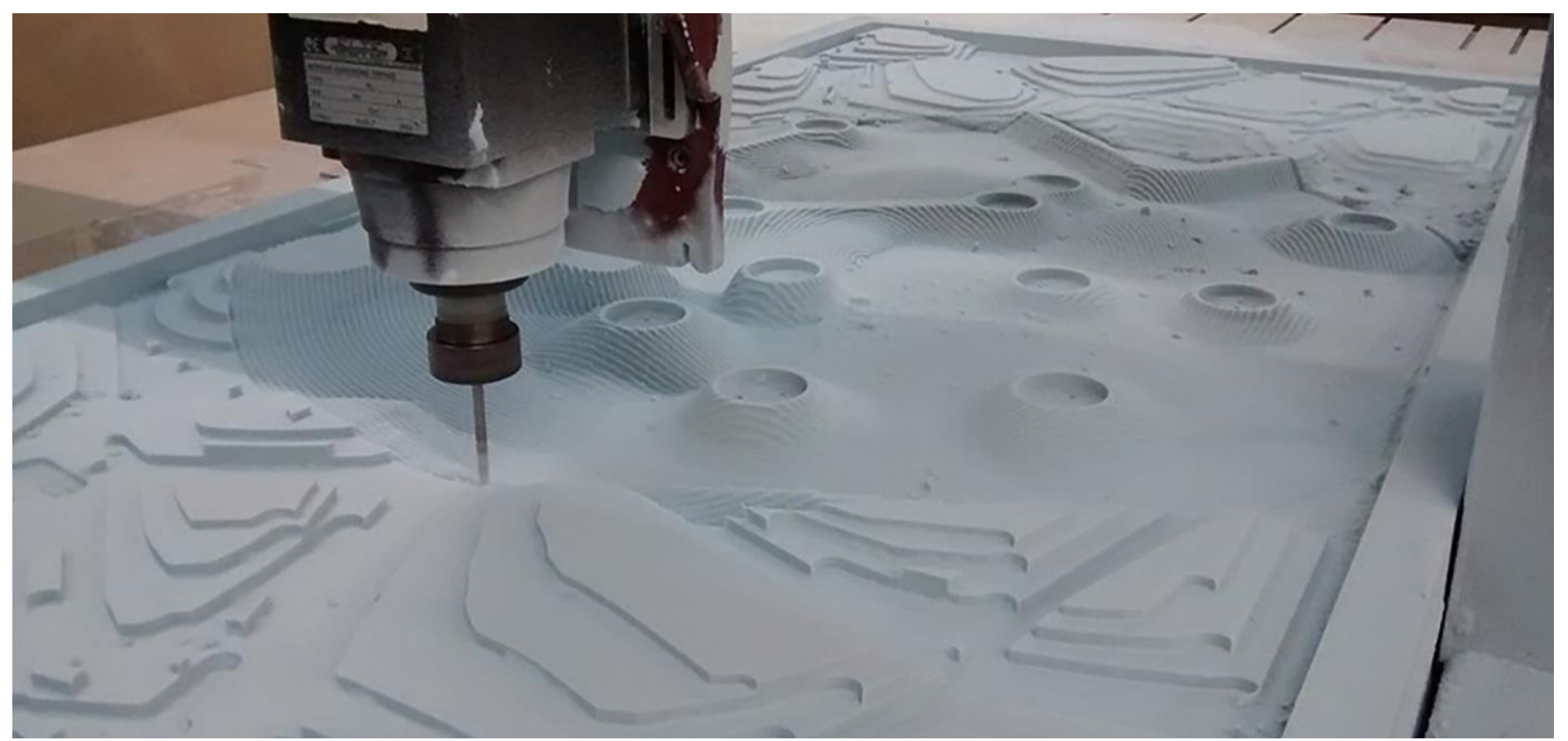

Figure 2 Milling machine executing the finishing process designed by each student, the organization followed the voronoi areas from the main structure. The G-code done by students was organized together by the milling tool. 


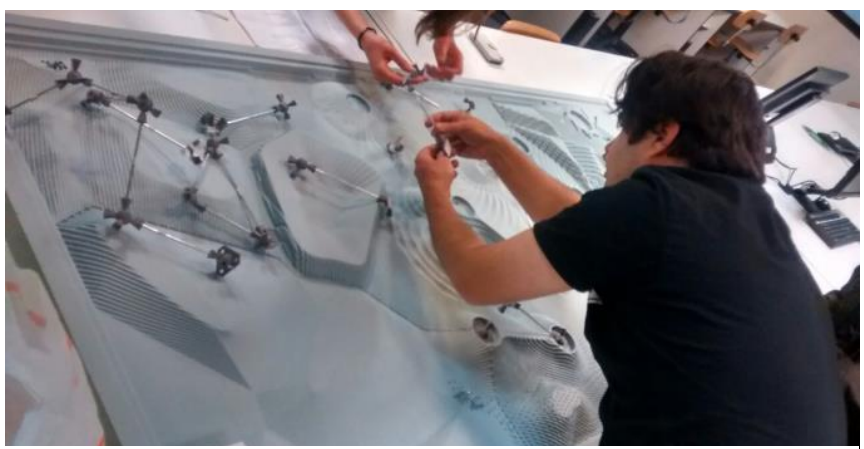

Figure 4 Biodigital Master students assembling 3dprinted joints according to aluminum bars numbering and to the foam panel.

Currently core curriculum of undergraduate disciplines do not exist any class related with Digital Fabrication, although if there is any, it has a false myth about Digital Fabrication being the last phase of the process. But practice is teaching us that there are some series of parameters can only be adjusted by experimentation.

We can only evolve technique using it and applying it on projects which demand the use of technologies. Precision that we would be able to achieve, from decimals to millimeters, require an extreme care from designers in all processes from begin to end, to achieve what in words of Sennett " $A$ well done work for the simple satisfaction of accomplish it" (un trabajo bien hecho por la simple satisfacción de conseguirlo)

The knowledge development in this area is mostly achieved by the exchange of experiences between different professionals working on digital fabrication. In the process, every single student learned, for this reason the result is made in a collective manner.

\section{Specifications}

\section{Machines}

FelixPrinter 3.1, Milling machine: AXYZ, Laser Cutter.

\section{Materials}

The base (FOAM): $2000 \times 1000 \mathrm{~mm}$, The joins (3d printer): PLA or Flexible, The envelope (Laser Cut): polypropylene, Aluminum bars.

\section{Software}

Rhinoceros, Grasshopper and add-ons (Kangaroo, BowerBird, WaverBird), Rhino3DPrint, RhinoNEST, RhinoCAM, Repetier for FelixPrinters, To fix STLS: https://modelrepair.azurewebsites.net/

\section{Acknowledgement}

We appreciate the collaboration of the students that have been interested on doing the workshops and contributing to the knowledge.

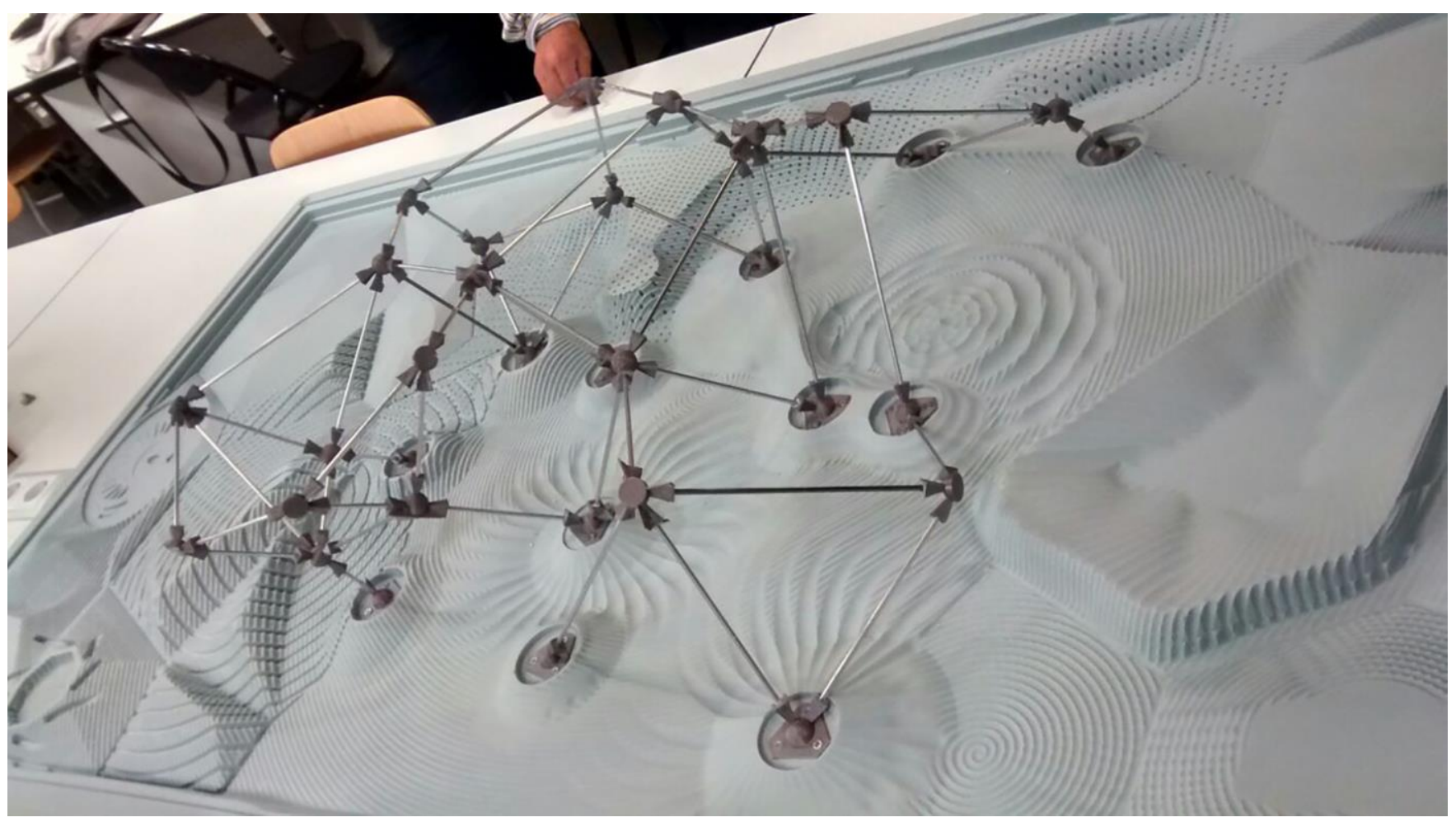

Figure 5 Final panel assembled by students. 


\section{References}

Charles McLean and Swee Leong, "The Role of Simulation in Strategic Planning," in Proceedings of the 2001 International Working Conference on Strategic Manufacturing (Aalborg, 2001).

DELEUZE, Gilles y GUATTARI, Félix. Rizoma (Introducción). Pretextos, Valencia, 1977.

IWAMOTO, Lisa. Digital Fabrications. Architectural and Material Techniques. Princeton Architectural Press. New York. 2009.

KOLAREVIC, Branko. Architecture in the Digital Age. Design and Manufacturing. Taylor and Francis. New York. 2003.

KOLAREVIC, Branko and KLINGER, Kevin. Manufacturing Material Effects. Rethinking Design and Making in Architecture. Taylor and Francis. New York. 2008
POTTMANN, Helmut... [et al.]. Architectural Geometry. Bentley Institute Press. Pennsylvania. 2007

SCHODEK, Daniel ... [et al.]. Digital Design and Manufacturing. CAD/CAM Applications in Architecture and Design. John Wiley \& Sons. New Jersey 2005.

SENNETT, Richard. El artesano. Anagrama, Barcelona 2009.

WINER, Norbert, Cibernètica i Societat. Edicions 62, Barcelona 1965. 